\title{
Electron Spin Resonance Dating of Shells from the Sambaqui (Shell Mound) Capelinha, São Paulo, Brazil
}

\author{
A. Kinoshita ${ }^{a, b}$, L. Figuty ${ }^{c}$, and O. Baffa ${ }^{a}$ \\ ${ }^{a}$ Universidade de São Paulo, DFM-FFCLRP, Av. Bandeirantes, 3900, 14040-901, Ribeirão Preto, SP, Brazil \\ ${ }^{b}$ Universidade do Sagrado Coração, R. Irmã Arminda 10-50 , 17011-160, Bauru, SP, Brazil and \\ ${ }^{c}$ Universidade de São Paulo Universidade de São Paulo, \\ Museu de Arqueologia e Etnologia, Setor de Arqueologia. Av. Prof. Almeida Prado 1466, \\ Cidade Universitária 05508-900, São Paulo, SP, Brazil
}

Received on 12 September, 2005; accepted on 10 November, 2005

\begin{abstract}
Capelinha is a fluvial sambaqui (Brazilian Shell Mound) located in the Ribeira Valey in the State of São Paulo that is being studied. It is one of the oldest sambaquis located along a river dated so far in this region. The use of ESR to date other shells stimulated our group to apply this method to the Capelinha site. Shells from land snails (Megalobulimus sp.) obtained in two levels of excavations were analyzed; one of them was in contact with a skeleton that was dated by C-14. The archeological doses obtained were $(8.05 \pm 0.07)$ Gy and $(9.50 \pm 0.03)$ Gy. Since the last site was previously dated by C-14 (Beta -Analytics, Beta 153988) giving: $8860+/-60$ years BP (conventional age) and 10180 to 9710 years BP (calibrated age), the archeological dose found for this shell was used to determine the local rate of $(0.93$ to 0.98$) \mathrm{mGy} / \mathrm{year}$, that aggress with other surveys done in the region. Using this dose rate the age of the second shell was found to be 8.14 to $8.73 \mathrm{ky} \mathrm{BP}$ that agrees with the stratigraphy of the site.
\end{abstract}

Keywords: ESR; Dating

\section{INTRODUCTION}

Sambaquis (Brazilian Shell Mound), also known as "concheiros", is an archaeological inheritance typical of the sea coast and fluvial areas were the population had as a cultural tradition to bury and cover its deceased with a thick layer of shells. Throughout all Brazilian coastal, specially in the southeast (Santa Catarina) there is a great occurrence of sambaquis, some of them are remarkable having up to $30 \mathrm{~m}$ of height formed from the accumulation of shellfishes and oysters.

The shells used in this work were collected on the Archaeological site Capelinha, located at Cajati City, State of São Paulo (latitude $24^{0} 50$ ' 80,7 longitude $48^{0} 14^{\prime} 38,1$ ), Brazilian Southeast. The Capelinha river is contributor of the Jacupiranguinha river in the basin of the Ribeira do Iguape river. In this valley a significant amount of fluvial sambaquis exists. In general way, they have circular shape with 500 to $1900 \mathrm{~m}^{2}$ of area and dimensions lesser than that the ones found in seacoast. The stratigraphic superposition in the burial structures as well as the great number of them suggest a long period of permanence in this area, probably for more than one generation. Fig. 1 show the location of the sambaquis already studied in this site. Different from the other sambaquis found along the coast, this one is composed of several small mounds that were built at different epochs and not a single large mound built layer after layer.

Due its particular geography, the Ribeira Valley is a zone where different cultures had entered in contact and possibly leaving an abundance of archaeological vestiges. In contrast to the majority of rivers in the State of São Paulo that start in the plateaus and run to west, the Ribeira do Iguape flows to east to the Atlantic. So it is a particular place to know and to study the prehistoric peoples established in an area considered as linking between the sea and plateaus.

Capelinha shell mounds were composed of shells of the genus Megaloblulimus. This site was first explored by amateurs in the mid-1980s, and calibrated dates of 10,500 year BP were founded. More recently AMS dating of collagen bone from one of the human skeletons recovered from the site yielded a non calibrated date of 8,860 \pm 60 year BP, confirming the early Holocene occupation of this site [1]. This skull is the oldest human skeleton founded so far in São Paulo State and this finding is showing the importance of more investigations in this area. Thus the dating of sites in this region is important to the knowledge of chronology and human occupation pattern of south Brazil as well as to contextualize the dating already realized. In this work the dating of shells from two levels of excavations was analyzed and the results shown good agreement with the stratigraphy.

\section{METHODS}

The shells used in this work belonged to two different levels of excavation: U-42 and I-10. Shells from U-42 level were involving the dated skeleton by C-14 (Beta -Analytics, Beta 153988) giving: $8860+/-60$ years BP (conventional age) and 10180 to 9710 years BP (calibrated age). The other shells belonged to an intermediary level of another position of the site. The deepest level of this place was also dated in Tucson (Laboratory of Isotope Geochemistry, University of Arizona), yielding $8795 \pm 100$ years BP.

The shells of each level were cleaned with water and acid etched in $20 \% \mathrm{HCl}$ in an ultrasound bath to remove the outer layer and dried in a silica gel at ambient temperature for several days. After this step they were gently crushed in small 


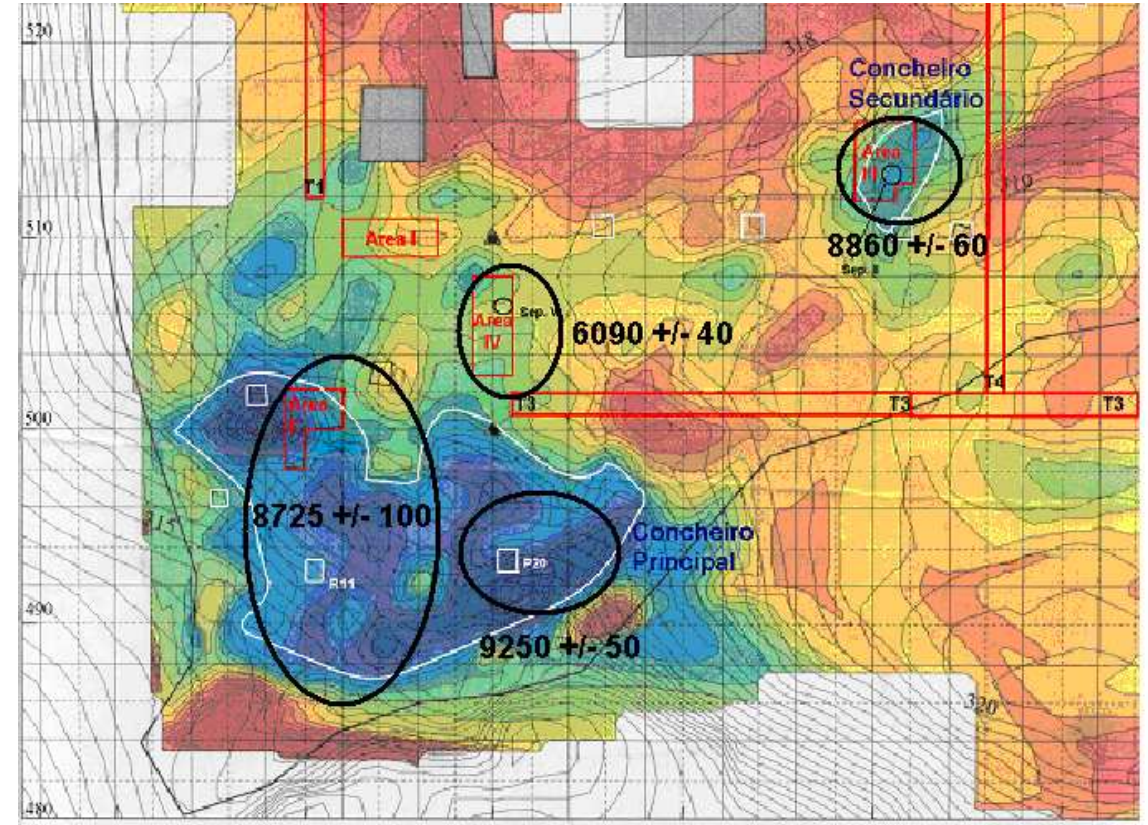

FIG. 1: A map of the location of the archeological site, showing the three sites (marked with circles) already excavated and dated. Ages range from $6 \mathrm{Ka}$ to $9 \mathrm{Ka}$ before present.

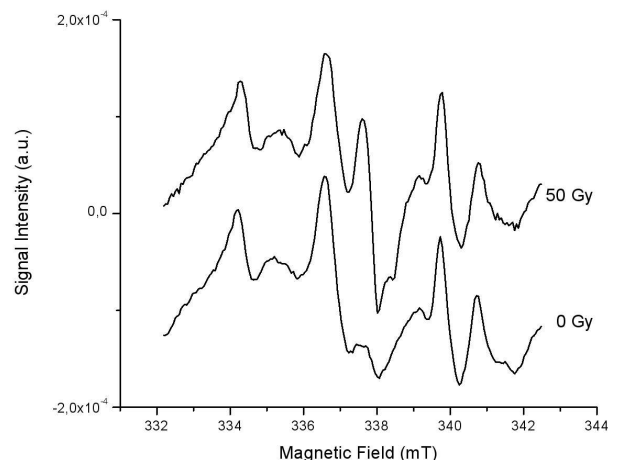

A

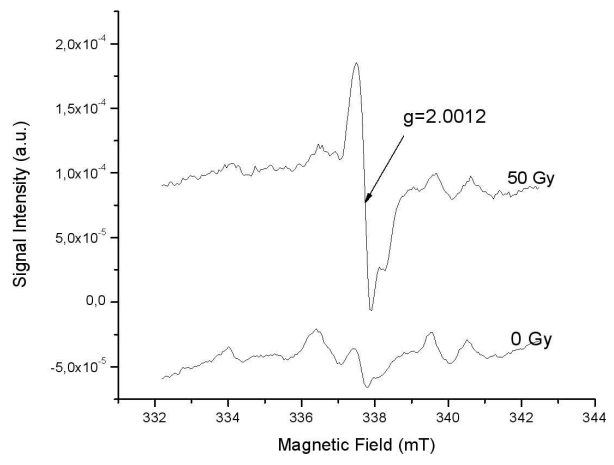

B

FIG. 2: ESR spectra of shells from the two levels of Capelinha Sambaqui - original spectrum and after added dose of 50 Gy. Sample (A) were extracted from level U42 and (B) from I10.

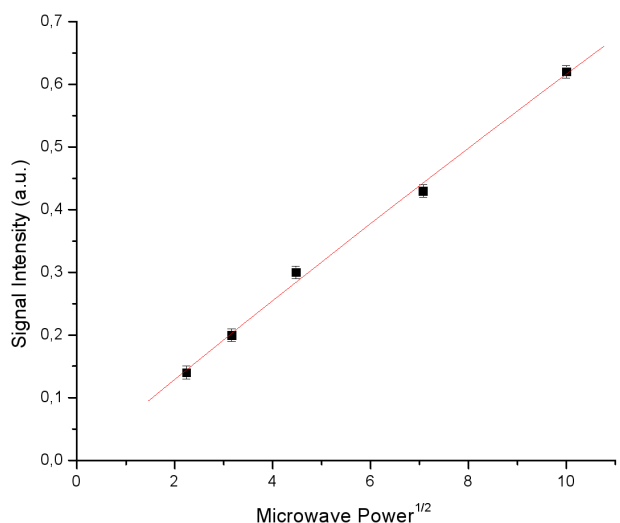

FIG. 3: Signal intensity as a function of microwave power, showing the non saturating power range.

particles smaller than $0.5 \mathrm{~mm}$ using an agate mortar and pestle. The powder obtained was divided in aliquots of about $100 \mathrm{mg}$ each and placed inside small plastic tube for irradiation. The irradiation was performed at Hospital das Clinicas de Ribeirão Preto USP, using a Radiotherapy equipment with Co-60 gamma source, with dose rate of $1 \mathrm{~Gy} / \mathrm{min}$. An estimated accuracy better than \pm 5 was achieved in the determination of the dose rate. A $0.4 \mathrm{~g} / \mathrm{cm}^{2}$ Lucite build-up cap was used over the samples. The doses delivered to samples were 1, 2, 3, 5, 10, 15, 20, 25, 30, 40 and $50 \mathrm{~Gy}$.

After irradiation, ESR spectrum of each sample was recorded to obtain a dose-response curve, using a Varian E4. The ESR spectrometer operates at X-Band $(9.5 \mathrm{GHz})$ with 


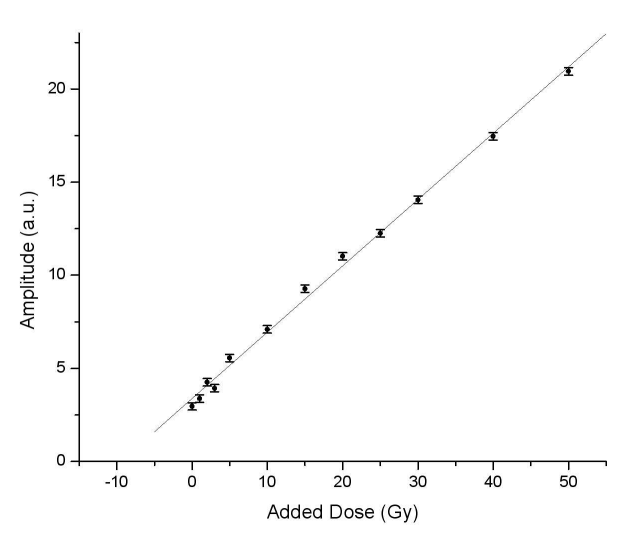

A

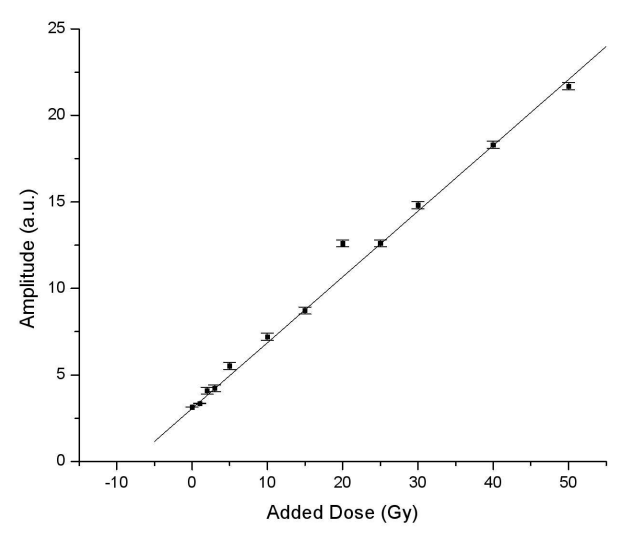

B

FIG. 4: Dose-response curve of shells from U42 and I10 respectively.

rectangular cavity (TE-102, model E-231). This spectrometer was improved by using a new digital lock-in amplifier and a computer acquisition system. The parameters used to record the spectra were Central field $338 \mathrm{mT}$; Scan Range $10 \mathrm{mT}$; Modulation Amplitude $0.2 \mathrm{mT}$; Modulation frequency 100 $\mathrm{kHz}$; Time constant $0.250 \mathrm{~s}$ and Microwave Power $20 \mathrm{~mW}$. The choice of the microwave power is important to improve a signal noise rate without saturation. This nominal power was chosen after the studying the saturation behavior of our sample, as shown in Fig. 3. The peak to peak intensities of the dosimetric signal at $\mathrm{g}=2.0012$ were normalized by the sample weight. A linear fit was used to the signal versus dose curve and a good agreement was founded with correlation coeffi- cient $R>99,5 \%$.

\section{RESULTS AND DISCUSSION}

The ESR spectra corresponding to the samples from two levels after cleaning without any laboratory radiation and after added dose of 50Gy are shown in Fig. 2. The dosimetric signal with Landé factor at $\mathrm{g}=2.0012$ is between 2 lines from $\mathrm{Mn}^{2+}$. Others authors also used this signal for dating [2].

The signal growth with microwave power is shown in Fig. 3 where it can be noted that the power of $20 \mathrm{~mW}$ is below saturation. The dose response curves of samples are shown in Fig. 4. The uncertainty in amplitude signal was calculated by de noise level divided by 2.5 . This is an approximation that overestimates the noise and it is adopted by many investigators [3]. As in Mascarenhas et al (1982) [4] and others [5, 6, 7 e 8] a linear fitting of ESR signal intensity versus dose were used, and the data appear to be in very good agreement $(\mathrm{R}>99.5 \%)$. The archeological dose $\left(\mathrm{A}_{D}\right)$ obtained are $\mathrm{A}_{D}=$ $(8.05 \pm 0.07) \mathrm{Gy}-\mathrm{I} 10$ shells and $\mathrm{A}_{D}=(9.50 \pm 0.03) \mathrm{Gy} \mathrm{U} 42$ shells. Considering the calibrated age obtained to the skeleton: 10180 to 9710 years and the archeological dose found for the shell from U42 level, the local rate is (0.93 to 0.98$)$ mGy/year. That agrees within $10 \%$ with a dose rate found in "Ponta da Flecha" cave, located at the Upper Ribeira Valley Karstic province, South of São Paulo State ( $24^{\circ} 38^{\prime} 38^{\prime \prime}$ S, $48^{\circ}$ $41^{\prime} 08$ ' W), a place near this site [7].

Using this dose rate the age of the shells from I10 level found to be 8.14 to $8.73 \mathrm{ky} \mathrm{BP}$. This result is in agreement with the statigraphy.

Some archaeological and paleontological studies already had been carried in this site [9-15]. This studies shows three different occupations in this region related to four different types of sites: fluvial sambaquis, lithic - associated to Umbu Tradition groups (hunters and collectors) from the late archaic period and ceramists, associated to Itaraté Tradition (horticultures group). However, the chronology still configures as a central problem for these occupation. Some datings presented by Collett \& Loebl [12] reach 10,000 years but lacks the adequate context. Thus systematic dating of these sites is very important and the ESR dating seems to be a good technique to this purpose since a few grams of shells and simple sample preparation is sufficient to produce an Archaeological Dose with good precision. New dating studies in this region will be able to support the hypothesis of these sites are older than sea occupation as suggested by Barreto [13].
[1] W. A. Neves, M. Hubbe, M. M. M. Okumura, R. GonzálezJose, L. Figuti, S. Eggers, and P. A. D. De Blassis, Journal of Human Evolution 48, 403 (2005).

[2] A. Molodkov, Quat. Sci. Rev. 20, 1051 (2001).

[3] Varian Associates, ESR E-line Century Series Manual 87-125607

[4] S. Mascarenhas, O. Baffa, and M. Ikeya, Am. J. Phys. Anthro- pol. 59, 413 (1982).

[5] A. Kinoshita, F. J. H. N. Braga, C. F. O. Graeff, and O. Baffa. Appl. Rad. Isot. 54, 269 (2001).

[6] A. Kinoshita, A. Brunetti, W. E. P. Avelar, F. L. M. Mantelatto, M. G. Simões, A. Francozo, and O. Baffa. Appl. Rad. Isot. 57, 497 (2002)

[7] O. Baffa, A. Brunetti, I. Karmann, and C. M. Dias Neto. Appl. 
Rad. Isot., 52, 1345 (2000).

[8] O. Baffa and S. Mascarenhas. ESR Dating of Fossil Shells from Sambaquis (Brazilian Shell Mounds). In: M. Ikeya (Editor), 1985, Tokyo. ESR Dating and Dosimetry. Tokyo, Japan: Ionics Co., 139 (1985).

[9] R. Krone. Revista do Inst. Hist., Geogr. e Geol. VIII(3), 1950

[10] E. Krug. Ribeira de Iguape. Secr. Da Agricultura, Comércio e Obras Públicas do Est. de S. Paulo, Typ. Brazil de Rothschield, São Paulo, 1908.

[11] G. C. Collet, Novas informações sobre os sambaquis fluviais do Estado de São Paulo. Arq. do Mus. De Hist. Natural 10, Belo Horizonte (1985).

[12] G. C. Collet and E. Loebl, Informações sobre os sambaquis fluviais do Estado de São Paulo. Anuário de Staden (Estudos Brasileiros), 36. Fundação Martius (Inst. Hans Staden), São Paulo (1988).

[13] C. N. G. B. Barreto. A ocupação pré-colonial do vale do Ribeira de Iguape, SP: os sítios concheiros do médio curso. MsC Thesis, FFLCH-University of São Paulo (1988).

[14] P. A. De Blasis. A ocupação pré-colonial do vale do Ribeira de Iguape, SP: os sítios líticos do médio curso. MsC Thesis, FFLCH-University of São Paulo (1988).

[15] E. M. Robrahn, A ocupação pré-colonial do vale do Ribeira de Iguape, SP: os grupos ceramistas do médio curso. MsC Thesis, FFLCH-University of São Paulo (1989). 